This item was submitted to Loughborough's Research Repository by the author.

Items in Figshare are protected by copyright, with all rights reserved, unless otherwise indicated.

\title{
Olympic sport and physical activity promotion: the rise and fall of the London 2012 pre-event mass participation 'legacy'
}

PLEASE CITE THE PUBLISHED VERSION

http://dx.doi.org/10.1080/19406940.2016.1229686

\section{PUBLISHER}

(C) Taylor \& Francis

\section{VERSION}

AM (Accepted Manuscript)

\section{PUBLISHER STATEMENT}

This work is made available according to the conditions of the Creative Commons Attribution-NonCommercialNoDerivatives 4.0 International (CC BY-NC-ND 4.0) licence. Full details of this licence are available at: https://creativecommons.org/licenses/by-nc-nd/4.0/

\section{LICENCE}

CC BY-NC-ND 4.0

\section{REPOSITORY RECORD}

Bretherton, Paul, Joe Piggin, and Guillaume S.P. Bodet. 2019. "Olympic Sport and Physical Activity Promotion: The Rise and Fall of the London 2012 Pre-event Mass Participation 'legacy'”. figshare. https://hdl.handle.net/2134/24060. 


\author{
Olympic sport and physical activity promotion: The rise and fall of the London 2012 \\ pre-event mass participation 'legacy' \\ Paul Bretherton*, Joe Piggin \& Guillaume Bodet \\ School of Sport, Exercise and Health Sciences, Loughborough University
}

\begin{abstract}
The legacies of Sport Mega Events (SMEs) such as the Olympic Games are increasingly regarded as significant opportunities to increase sport and physical activity (PA) participation. Major sport/PA legacy objectives may even be pursued before the event takes place. This paper examines a specific pre-event sport/PA policy target of the London 2012 Olympic Games: the aim of increasing overall participation by two million between June 2008 and the Games in 2012 (a target which was abandoned in 2011).

Within a governmentality analytical framework, this research examined how London 2012's pre-event sport/PA participation legacy targets were constructed by organisations responsible for their delivery. Three specific themes are discussed: the inconsistency between how sport/PA participation was constructed in terms of both 'risk' and 'reward' by different organisations; the reliance upon intangible concepts such as 'inspiration' and the status of the Olympic Games to increase participation; and the rationales given for the subsequent abandonment of the pre-event PA participation targets in 2011.
\end{abstract}

The abandonment of the pre-Games participation targets holds two overarching policy implications for future SME host governments and organisers. First, host governments cannot rely on the unique status or 'inspiration' of the Games alone to increase participation and must pursue this more proactively. Second, the ultimate failure of these policies should not be attributed exclusively to their intrinsic limitations, but also to a range of external environmental factors. Pre-event SME legacies must therefore be planned with sufficient awareness of the social and political contexts in which the event takes place.

Keywords: Olympic Legacies; Sporting Legacies; Sport Policy; Physical Activity Policy; Governmentality;

For the UK Government, the "first priority" of the London 2012 Olympic Games was "to make the UK a world-leading sporting nation" (DCMS, 2008, p. 3). Seeking to capitalise upon the 'inspiration' of the Games in the years leading up to the event, the UK public were encouraged to become "increasingly active, with a goal of seeing two million people more active by 2012" (DCMS 2008, p. 3). Within this overall pre-event target of two million, one million more people were to begin participating in sport and another million were to take up

*Corresponding author. Email:p.a.bretherton2@gmail.com 
P. Bretherton et al.

PA by 2012. These aims were ambitious. Had the target of one million more people taking up sport by 2012 been met, it would have represented a 15\% increase in participation following two decades without progress (Bullough 2012).

Despite the optimism with which these targets were announced, three years of limited progress saw the UK Government acknowledge their abandonment by 2011 (Weed 2013; Kelso 2011). Several months before the Games began, a new sport participation legacy strategy was published with a narrowed focus upon youth participation (DCMS 2012). On one level, this shift of emphasis represented a quantifiable failure of an Olympic host government attempt to fulfil a published pre-event legacy objective. More broadly, this policy change must be understood within a broader context that witnessed both economic instability and a change of UK Government in May 2010. This fluid political environment saw extensive debates around sport policy issues such as funding for School Sport Partnerships (SSPs) and a perceived UK Government shift towards "sport for sport's sake" (Devine 2013, p. 257) instead of mass participation sport.

Since 2012, sport has been further prioritised as a vehicle for increasing PA and public health, as demonstrated by Sport England's Get Healthy Get Active funding stream as well as a change in government policy emphasis from the measurement of participation to that of physical and mental health alongside individual, community and economic development (UK Government 2015). Although further measurement and evaluation will be required to determine if these approaches - and the participation legacy of London 2012 ultimately prove successful, the abandonment of the DCMS's pre-event participation legacy targets merits specific attention. With aspiring Olympic hosts increasingly required to demonstrate how the event will bring about long term social benefits (Fussey et al. 2011), the abandonment of these pre-event participation targets has important implications for future SME hosts. 
The current research aimed to understand more about how the proposed London 2012 sport/PA participation legacy was constructed and adjusted by key policy actors between 2003, when the UK Government confirmed that London would bid for the 2012 Games, and 2012, when the event took place. This is not to say that the year 2012 represented the end of policy attempts to realise a sport/PA participation legacy from London 2012, but that this research focuses specifically on both the rhetoric of the bidding stage and the pre-event sport/PA targets published in 2008. Drawing upon a governmentality analytical framework (Foucault 1994), policy material published by four organisations (UK Government, Greater London Authority, Sport England, London 2012 Bid Team/LOCOG) was analysed in order to better understand the challenges that domestic sport/PA policy must overcome in seeking to better implement pre-event social legacies around SMEs.

\section{Olympic legacies}

Research on SME and Olympic legacies has increased as the concept has become more formalised over time (Lepokey \& Parent 2012a; Cashman 1999). Notable trends include the consideration of tangible/intangible, hard/soft and physical/spiritual legacies as well as broader legacy areas such as transport, infrastructure, volunteering, employment, sport policy and sport participation (Chappelet 2012). The Olympic Games in particular has been associated with the notion of long term benefit from its modern revival onwards, but in recent years these benefits have "evolved from general benefits and impacts of the Games to sustainable long-term legacies, which have been strategically planned from the time of the bid” (Leopkey \& Parent 2012a, p. 938).

This reference to intended legacy 'benefits' is important, as it is in these positive terms that Olympic legacies are primarily articulated by organisers and host governments. For example, Gratton and Preuss (2008) identify how Olympic legacies may be understood as 
P. Bretherton et al.

positive or negative, planned or unplanned and tangible or intangible. Beyond the recognition that legacy is not inherently positive, the possibility that legacies may be unplanned or intangible also illustrates the social complexity faced by policymakers who may seek to use the Games to bring about desirable changes in the host nation. As the scope and formality of potential Olympic legacies have increased over time, these legacies have also been shown to be increasingly shaped by discursive construction (MacAloon 2008). Furthermore, Agha, Fairley and Gibson (2011) describe how the fact that an Organising Committee of the Olympic Games (OCOG) disbands within two years of the event gives rise to "a series of broad legacy claims” (p. 126) that are further complicated by the multitude of different organisations involved in the event's delivery (Chappelet \& Kübler-Mabbott 2008).

A milestone event in the development of Olympic legacy planning was the 2002 amendment of the Olympic Charter to include the statement that one of the IOC's official roles is "to promote a positive legacy from the Olympic Games to the host cities and host countries” (IOC 2013a, p. 17). Fussey et al. (2011) describe how recent Games of the 21st century have seen the IOC set OCOGs the requirement to "adopt more environmentally and socially responsible approaches to planning" (p. 29) for the Games, which has seen heightened importance attached to considerations of legacy and regeneration in evaluations of the Games. The IOC (2013b) present these 'social responsibilities' in five thematic categories: 'cultural/social/political', 'environmental', 'economic', 'urban' and 'sporting', and although each OCOG must consider all five within its planning and delivery of the Games, it was the 'sporting' legacy of London 2012 that was described as "'first among equals' in the minds of the IOC, LOCOG, the government and the UK media" (Weed 2013, p. 95). Within this overall sporting legacy, London 2012's pre-event sport/PA participation targets represented a clear example of a contemporary Olympic legacy policy in terms of both their proactive 
timescale and as a proclaimed attempt to use the event to positively influence individual behaviour.

There is a clear link between the positive phrasing which accompanies host governments' and policy-makers' claims about the overall legacy of the event and the specific area of sporting legacies and sport more broadly. For Kay (2012), the underlying commitment of the Olympic Games to social change manifests itself in how it is "captured in the notion of legacy", which is in turn based upon a "powerful advocacy" (Kay 2012, p. 899) of sport's inherent social potential. These positive assumptions are evident in academia (e.g. Smith \& Westerbeek 2007) as well as contemporary UK sport policy. For example, Grix and Carmichael's (2012) conceptualisation of a 'virtuous cycle of sport' articulates how elite success, increased participation and the widening of a national 'talent pool' are suggested to work together in cyclical fashion. But despite the enthusiasm with which sport's social potential may be advocated, there remains a lack of consistency in how it can be defined and understood. For example, Grix and Carmichael (2012) note that UK Government policy discourse "does not always clearly distinguish between participation in 'PA' or a more formal 'sport"' (p. 84), and such a lack of clarity can make it difficult to understand precisely which form of activity is being referred to in public statements that may conflate sport and PA in both competitive and non-competitive settings, as well as their intended implications for health.

\section{The sport and PA participation legacy of London 2012}

London 2012's legacy visions sought distinction "from both previous editions of the Games and from its bid competitors" (Weed 2013, p. 87). Within this overall vision, London 2012's unprecedented commitments to health promotion (Commission for a Sustainable London 2012 2011) were a central component. In relation to the DCMS's (2008) pre-event 
mass participation targets, the announcement of these objectives highlighted the "general health benefits" (p. 22) of completing five 30-minute sessions of PA per week, thus setting out the presumed positive correlation between this level of sport/PA participation and health promotion. However, before the publication of London 2012's pre-event participation targets, research on previous editions of the Olympic Games had demonstrated only a negligible increase in adult participation both in the host nation (Tsouros, Stergachi \& Barbeschi et al. 2007, Veal 2003, Bauman, Ford \& Armstrong 2001) and in other countries (Hindson, Gidlow \& Peebles 1994) following the event. These conclusions are consistent with the results of several reviews of the evidence base for the effect of major sporting events upon sport/PA participation (Mahtani et al. 2013, McCartney et al. 2010, Weed et al. 2009, Murphy \& Bauman 2007).

This evidence does not necessarily prove that any attempt to increase participation using the Games is impossible (McCartney et al. 2010, Weed et al. 2009), but there are a range of factors that make both achieving and measuring (Wellings et al. 2011) a participation increase particularly problematic. For example, there is no evidence that the staging of the event alone is sufficient to inspire a 'trickle down' or 'demonstration' effect that encourages participation automatically (Weiler \& Stamatakis 2010), and legacy planners must also recognise that efforts to capitalise upon the presumed inspiration of the Games require the systematic cooperation of numerous domestic sport organisations (Coalter 2004) and effective leadership at local level (Charlton 2010). For Girginov and Hills (2008), the UK Government's attempt to use London 2012 to increase sport/PA participation represented "the most ambitious project in the history of the Olympic Games" given both its scope and its task in addressing "not only people's behaviour but also deeply rooted social structures" (p. 2092). Weed et al. (2012) advise that because of the need for a sport/PA participation legacy to be brought about proactively - given concerns around a demonstration effect in relation to the 
least active adults - policymakers would be best advised to emphasise participation in PA ahead of sport, such as by generating a festival effect around the Games that emphasises its reach beyond sport alone and into local communities.

Beyond these technical issues, the need to address certain social structures and relations also depends upon wider political dynamics. For Murphy and Bauman (2007), the successful use of SMEs to increase mass participation depends upon successful cooperation between the health and sport sectors - who can potentially find themselves in direct competition with one another (Weiler \& Stamatakis 2010). Furthermore, the role of social and political factors in shaping the sport/PA participation legacy of London 2012 is noted by Girginov and Hills (2009), for whom Olympic legacy features "contested and complex aspects" that may be "defined and operationalised according to multiple interests and objectives" (p. 165). These accounts of how Olympic legacies must be understood within broader political processes are consistent with both the growth of sport as a public policy concern (Green \& Houlihan 2006) and the increasing social responsibilities expected of Olympic hosts (Fussey et al. 2011). With this understanding of Olympic legacy established, this research's theoretical perspective is presented next.

\section{Research approach: Governmentality perspective}

This research is guided by Foucault's (1994) conceptualisation of governmentality. For Foucault, governmentality could be understood as:

The ensemble formed by the institutions, procedures, analyses, and reflections, the calculations and tactics that allow the exercise of this very specific albeit complex form of power, which has as its target population, as its principal form of knowledge political economy, and as its essential technical means apparatuses of security (p. 219). 


\section{P. Bretherton et al.}

In the second and third parts of this definition, Foucault describes how in the West, a form of power known as 'government' has gradually gained pre-eminence, leading to "a whole series of specific governmental apparatuses" and "a whole complex of knowledges" (p. 220), a process that can be traced to the "state of justice of the Middle Ages" (p. 220). Here it is worth noting Markula and Pringle's (2006) observation that significant parallels can be drawn between Foucault's original work and contemporary sport and exercise - despite Foucault not addressing these areas directly. This research uses Foucault's original work as a starting point but focuses primarily upon more recent sources that have both advanced the concept of governmentality and applied it in the contexts of modern sport/PA policy.

A governmentality analytical approach examines the way that power is shared among "a whole variety of authorities" that "govern in different sites, in relation to different objectives" (Rose, O'Malley \& Valverde 2006, p. 85) and is never absolute or exclusive. For Dean (1999), government refers to "any more or less calculated and rational activity" and can be performed by "a multiplicity of authorities and agencies" that may use "a variety of techniques and forms of knowledge" in order to shape conduct (p. 18). Dean's articulation is directly applicable to the London 2012 sport/PA participation legacy, which represents a explicit attempt to influence individual behaviour that is coordinated by a range of different public (and private) organisations. This author's reference to 'shaping conduct' also resonates with the way that governmentality research is typically applied to 'neoliberal' societies in which conduct cannot be controlled explicitly. On this note it has been levelled that "neoliberalism has been "increasingly used in a pejorative sense as dismissive shorthand by critics" (Heynen et al. 2007, p. 3) - to which Ferguson (2009) argues that "if we can go beyond seeing in "neoliberalism" an evil essence or an automatic unity" it is possible to "see a field of specific governmental techniques" (p. 183) that may be used more constructively by researchers. This research approaches and deploys governmentality in line with both Dean 
(1999) and Ferguson (2009), taking the view that, although ideologically-driven, 'governing' represents a set of techniques or tactics that can be performed or resisted by multiple entities as opposed to the inherently dystopian or 'evil' essence described by Heynen et al. (2007).

For Osborne (1997), "governments can at best provide the conditions" to encourage people to adopt healthy lifestyles but "cannot guarantee health as such" (p. 179). This impossibility of 'guaranteeing' health is consistent with more recent accounts of 'steering' (Vallentin and Murillo 2011) or 'nudging' individuals towards desired behaviours (Vallgårda 2012), that cannot be explicitly coerced. As shown by McDermott (2007), one example of how individual behaviour may be shaped in relation to health is through the use of 'risk discourses' in which "physical inactivity and obesity are understood as due to an individual's inability to make the "right" choices to commit to a healthy lifestyle" and therefore function as "moral technologies" that help to guide individual conduct (p. 318). The specific case of sport/PA participation represents one area of public health promotion to which these observations can also be applied.

Where sport/PA policy is concerned, recent decades have seen national governments significantly increase their interest (Green and Houlihan 2006) and investment (Grix 2015) in sport - an increase that has seen the governance of sport undergo significant changes. For Green and Houlihan (2006), a governmentality perspective offers ways of moving beyond the "straightforward assumptions" (p. 67) upon which many policy analyses have been based and enables better analysis of processes such as autonomisation and responsibilisation in the context of national sport organisations. Similarly, Grix (2015) describes how while sport studies have been relatively slow to draw upon the "mature debates" (p. 24) of political sciences, approaches such as the 'governance narrative' - which shifts focus from 'big government' to more indirect processes of governing through networks, partnerships and devolution - and governmentality, which encourages both "individual and institutional 


\section{P. Bretherton et al.}

conduct which is consistent with government objectives (p. 126). Along these lines, Piggin, Jackson and Lewis (2009) used a governmentality approach to establish "how certain governing ideas within sport and recreation policy are formulated" such as encouraging PA participation and "promoting ideas about the value of elite sporting success" (2009, p. 89). In terms of the Olympic Games specifically, Chatziefstathiou and Henry (2009) assert that Olympism "operates as a source of governmentality" and represents "an overt philosophy of behaviour" that provides values, principles and behaviours that holds legitimacy from micro to macro levels of society (p. 4).

These examples bear out the distinction between 'government' - the official structures which set formal policy - and 'governing'/'governmentality' - which refers to a more abstract set of 'tactics' (Foucault 1994) and 'techniques' (Ferguson 2009; Dean 1999) that may be used to shape individual conduct in relation to wider objectives. A governmentality perspective is particularly suitable for the present study as it enables a more sophisticated of government targets that concern an area of population management that is inherently uncontrollable and demands the use of more indirect forms of governance. Furthermore, the increased political use of sport by governments (Grix 2015; Green \& Houlihan 2006) along with the specific values and behaviours advocated by the Olympic Games (Chatziefsthatiou \& Henry 2009) demonstrates how the London 2012 sport/PA participation legacy represents an ideal site to approach with the broader complexity offered by a governmentality perspective.

\section{Methods}

This research aimed to understand more about how the proposed London 2012 preevent sport/PA participation legacy objectives were constructed by selected policy actors between the UK's official decision to bid for the 2012 Games in 2003 and the staging of the event in 2012. The focus was therefore not upon the sport/PA legacy policy of the Games as a 
whole, which has continued to develop since 2012 and as a post-event Olympic legacy may require at least 15 years to be accurately measured (Gratton \& Preuss 2008). Specifically, the emphasis of this study was upon policy content pertaining to the pre-event sport/PA participation targets - encompassing both the broader claims published in the bidding stage and the specific pre-event sport/PA participation legacy policies that were published following London's selection as host in 2005.

As documentary content allows access to political processes that would otherwise be inaccessible (Harrison 2001), this research analysed policy documents and media articulations of certain policy developments produced by selected organisations between 2003 and 2012. The increasing number of organisations involved in the delivery of the Games (Chappelet \& Kübler-Mabbott 2008) further emphasises the practical need to limit the organisations selected for analysis, and data collection therefore focussed upon policy published by four state organisations: the UK Government's Department for Culture, Media and Sport (DCMS), the Department for Health (DH), Sport England and the Greater London Authority (GLA) along with the London 2012 Bid Team/LOCOG. The emphasis upon state organisations is attributable to the fact that host governments are chiefly responsible for Olympic legacy planning. LOCOG was also selected on the basis that "the legal form of an OCOG is increasingly becoming that of a government agency" (Chappelet \& Kübler-Mabbott 2008, p. 91). The selection of documents was restricted to policy documents authored exclusively by the organisations named in this section. For example, although the official DCMS meta-evaluation of the Games features extensive work upon the sport/PA legacy of the Games, its authors acknowledge that no guarantees can be made regarding the 'accuracy' or 'completeness' (DCMS 2011) of the contributions made to this work by external organisations. 
Although the selection of specific organisations may risk ignoring important policy articulations from others, the advantage of focussing upon the five listed here was that it better enabled the researchers to identify contradictions and inconsistencies in material produced by the same organisation(s) over an extended period of time. In choosing relevant organisations, emphasis was placed upon state organisations that held a national level responsibility for the design and delivery of the legacy of the Games. International bodies such as the IOC and regional organisations such as the Nations and Regions Group were therefore not considered. Focus was also restricted to policy around the Olympic Games and mass sport/PA participation - thus excluding that concerning the Paralympic Games and the legacy for disability sport, primarily owing to the scope of the study and the extra debates and issues that would be entailed. As the UK Government's size demanded that only certain departments were used for analysis, departments were selected on the basis of their contribution to the published sport and activity participation legacy targets of London 2012. Despite the change of UK government in 2010, this research treats the UK Government as one consistent entity as the foremost concern was its role as an Olympic host government as opposed to any comparison between different UK administrations.

The one exception to the above criteria was the Greater London Authority's (2009) A Sporting Future for London, as London's high population distinguishes its role in promoting sport in London from those of other local organisations. With these criteria established, specific documents were selected purposively (Silverman 2010), on the basis that they either concerned the sport and activity participation legacy specifically, or - more commonly covered this as one of several strands of the event's legacy as a whole - either in terms of its initial proposal, planning or adjustment (such as those made following the change of Government in 2010). Also included was the UK Government's 2011 Public Health 
Responsibility Deal, on the basis of its content regarding responsibility for public health in the years around London 2012.

From these sources, 16 policy documents with a total combined length of 642 pages were analysed. These documents provided official accounts of the various stages of the sport/PA participation legacy's proposal, planning and delivery within the broader context of the event's legacy as a whole. Additionally, extra sources were collected that pertained to four significant events in the development of the sport/PA legacy that were not completely covered in official documents: the first official announcement of London's intention to bid for the Games in 2003, its selection as host city for the 2012 Games in 2005, the 2010 announcement of Places People Play and the 2011 admission that the pre-event sport/PA participation targets had been abandoned. In order to address these gaps, a further 30 pages of data were collected, which took the form of speeches and media articulations of specific policy developments. The overall dataset consisted of 22 different sources which contained a total of 672 pages of content. A full timeline of the key events in the development of the sport/PA participation legacy and the documents used for analysis is provided in Table 1.

Analysis of the selected documents followed Braun and Clarke's (2006) six phases of thematic analysis (familiarisation with data, generating initial codes, searching for themes, reviewing themes, defining and naming themes, producing the report), but with one modification. This concerned the initial reading of the documents, where one preliminary stage was added in order to establish whether content related to sport and activity participation legacy - with unrelated content being disregarded. This was particularly necessary in the analysis of documents that covered every aspect of the event's legacy, which were defined by the DCMS (2008) as including "making the UK a world-leading sporting nation", "transforming the heart of East London", "inspiring a new generation of young people", "making the Olympic Park a blueprint for sustainable living" and "demonstrating 
P. Bretherton et al.

that the UK is a creative, inclusive and welcoming place to live in, visit and for business" (p. 1). Within these legacy areas, the sport/PA participation legacy was detailed underneath the first 'promise' (to make the UK a 'world-leading sporting nation'), which in turn was divided into three headline ambitions: "inspiring young people through sport", "getting people more active" and "elite achievement" (DCMS, 2008, p. 6). Furthermore, it is worth clarifying that the term 'sport/PA participation legacy' as used in the present document does not refer to "elite achievement" - as the focus of the study was upon mass participation sport and discretionary/leisure PA. Material pertaining to elite sport was therefore disregarded.

(Table 1)

\section{Findings and analysis}

\section{Constructions of sport/PA and their relationship with health}

Across the documents examined, there was significant inconsistency in how 'sport' and 'PA' participation were constructed in terms of their intended effects upon public health and wider society. On a definitional level, some sources claimed a clear distinction between sport and PA (Sport England, 2008) while others acknowledged that "on the ground the division is far more blurred" (GLA 2009, p. 9). Beyond these terminological issues, sport's social value was articulated in varying ways. For example, the DCMS (2008) emphasised the risks of failing to use the Games to promote PA participation:

By 2050 60\% of men and 40\% of women could be clinically obese, if we do nothing. The London 2012 Games are our best chance in a generation to encourage people to be more physically active and to give them the opportunities they need to do so (DCMS 2008 p. 22). 
This warning is consistent with the empirical evidence that no previous Olympic Games has been proven to have caused a permanent increase in PA participation (Tsouros, Stergachi \& Barbeschi et al. 2007, Veal 2003, Bauman et al. 2001). The use of statistics to emphasise the importance of using London 2012 to succeed where its predecessors could not resonates with accounts of how 'tactics and calculations' (Foucault 1994) and 'techniques' and 'forms of knowledge' (Rose et al. 2006) contribute towards the process of governing and shaping individual conduct. In this case, ostensibly scientific predictions around obesity rates based on current statistics are set against the one-off nature of the Games in order to emphasise the vital effort required to increase PA. This logic also resonates with the notion of 'risk discourses' (McDermott 2007) which function in (neo-liberal) societies where populations are understood in relation to "discourses of responsibilisation, choice and self-governance" and issues such as individual health/obesity are therefore linked to the inability of individuals "to commit to a healthy lifestyle". A 'risk discourse' therefore acts as a "moral technology" through which "regulatory practices seeking to shape and guide people's conduct are deployed" (2007, p. 318). A similar logic can be seen in the present example, as the DCMS's rationale is primarily phrased in indirect terms such as 'providing opportunities' and 'encouraging' increased participation. Despite these parallels with McDermott's (2007) understanding of how 'risk discourses' may be used in the promotion of healthy lifestyles, the specific context of the London 2012 Olympic legacy features a number of additional factors that must be considered in relation to the dynamics of sport/PA and health. These include the link between these issues of individual responsibility and the one-off nature of the Games (DCMS 2008), as well as the proclaimed broader benefits of sport/PA, such as the assertion that PA participation "boosts concentration and feeds through directly into improved academic performance" (DCMS, 2010, p. 2). 
This focus upon the 'risks' or negative consequences of failing to promote sport/PA was not the only way in which the unique opportunity offered by London 2012 was articulated. Other sources approached the issue in more positive terms, emphasising the broader positive consequences of sport/PA instead:

Sport can act as a great leveller - allowing people from all backgrounds to come together and join in positive activity. It can help our young people stay healthy, and it can help tackle issues such as obesity, academic underachievement and crime (Johnson, cited GLA 2009, p. 5).

This paean to sport, authored by then Mayor of London Boris Johnson, echoed Sport England's (2008) assertion that "sport can and does play a major role in achieving wider social and economic benefits - notably on the health front" (p. 1). While these positive views of sport are long-established (e.g. Smith and Westerbeek 2007), this emphasis upon the rewards of sport/PA participation contrasts with the warnings of the 'risks' of failing to participate examined above. Just as a 'risk discourse' can be used as one indirect means of promoting health (via sport/PA), these articulations of the potential incentives of sport/PA participation suggest that a parallel 'reward discourse' could be argued to function similarly. These policy emphases upon 'risk' and 'reward' are comparable in how both can be understood as indirect attempts to 'steer' (Vallentin \& Murillo 2011) individuals towards desired behaviours that cannot be brought about by direct coercion. Beyond this similarity, the more optimistic emphasis upon potential rewards or benefits of sport/PA participation could be linked to the unique status of sport - and indeed the Olympic Games - in relation to broader goals such as community development (Grix \& Carmichael 2012) and social integration (Smith \& Westerbeek 2007). 
Three features of the evidence examined in this section can be seen as factors which may have facilitated the use of indirect governmental techniques such as 'risk' and 'reward' discourses. First, the inherent difficulties faced by governments in trying to promote health (Osborne 1997) - in this case via sport/PA participation - and sport/PA participation (e.g. Grix \& Carmichael 2012; Weed et al. 2012) represent significant challenges. Second, the increased planning and social responsibilities demanded of Olympic legacy planning (e.g. Leopkey \& Parent 2012a; Fussey et al. 2011) are consistent with how the claims examined in this section moved beyond the proclaimed benefits of sport/PA alone and extended into other areas such as education and crime. Third, the deployment of the indirect governmental techniques described here can be seen more broadly as symptomatic of sport's growth into a major public policy concern (Grix 2015; Green \& Houlihan 2006). Overall, this illustration of how both the 'risks' and 'rewards' of sport/PA participation were emphasised in policy relating to London 2012's pre-event participation targets demonstrates how Olympic legacies are both long term exercises in social responsibility (Fussey et al. 2011) and social constructions that can be continually reshaped and contested. In terms of sport/PA participation legacy targets and PA policy in general, the chief implication of this evidence is that appreciating the social complexity of precisely what constitutes sport or PA - and the ultimate effects of these constructs upon 'health' - is a clear requirement for Olympic legacy planners and sport/PA policymakers.

\section{'Inspiration': The unique nature of the Olympic Games}

Although certain features of UK state policy around the legacy of London 2012 can be understood in relation to longer term trends regarding sport/PA's status in contemporary politics, others were more explicitly connected to the specific context represented by the Olympic Games. The perceived special status of the event was most readily apparent in the 
P. Bretherton et al.

intangible notion of 'inspiration' and became heavily linked to the proposed sport/PA participation legacy following Lord Coe's speech to the IOC before the final vote in Singapore:

We can no longer take it for granted that young people will choose sport. Some may lack the facilities. Or the coaches and role models to teach them. Others, in an age of 24-hour entertainment and instant fame, may simply lack the desire. We are determined that a London Games will address that challenge. So London's vision is to reach young people all around the world. To connect them with the inspirational power of the Games. So they are inspired to choose sport (Coe 2005, para. 36-40).

Coe's vision implies that factors in increasing participation such as coaches and role models are best provided by the Olympic Games. This assumption resonates with Chatziefstathiou and Henry's (2009) account of Olympism's historical capacity to define itself as "the reference point for what constitutes sport" (p. 24-5). Coe's emphasis upon the 'inspirational power' of the Olympics in relation to young people was soon echoed in UK Government policy. In its official legacy plans, the DCMS proclaimed that the Games would "inspire every person, young and old, to take part in a range of sporting activities and to lead healthier, more active lives" (p. 19) while in 2010 Coe himself announced Places People Play with the statement that it would "harness the inspirational power of the Games to promote sport and leave a lasting legacy of facilities" (Coe, cited in Slater 2010, para. 27). These examples illustrate how early references to the unique 'inspiration' and 'power' of the Games evolved into formal statements about how the event could bring about a mass sport/PA participation legacy despite substantial evidence to the contrary (e.g. McCartney et al. 2009; Weed et al. 2008). 
This inconsistency between the apparent reliance upon the 'inspiration' and 'power' of the Olympic Games in official legacy policies and the practical challenge of increasing participation points to a deeper contradiction. On the surface, 'inspiration' resonates with the broad view that hosting sport events can generate "civic pride, self-confidence, or a festival atmosphere" (Burgan \& Mules 1992, p. 709); three intangible constructs that are difficult to prove (or disprove). However, the specific use of 'inspiration' in relation to the London 2012 sport/PA participation legacy can be linked to more complex assumptions upon which the Olympics are based. Central to these assumptions is the concept of Olympism, which has been described as a "philosophy of behaviour" or "set of values" accepted across the global context of world sport that may also be internalised at individual level (Chatziefstathiou \& Henry 2009, p. 4). This understanding of the Olympic Games both helps to explain the unique status they enjoy in contemporary sport and underpins the references to 'inspiration' in relation to sport/PA participation examined above. In terms of the broader workings of governmental tactics (Foucault 1994), this example demonstrates how the use of 'inspiration' represented a specific means for UK policy to link the global status of the Olympics to a set of established assumptions regarding individual conduct in relation to sport and physical culture.

From the bidding stage onwards, the inherent 'inspiration' and 'power' of sport and the Olympic Games were also deployed enthusiastically in relation to broader social objectives than sport and PA participation alone:

Throughout our country there is an appreciation that the Olympic Games and Paralympic Games are a power for good. For London 2012, that power for good will be the most powerful catalyst imaginable for the regeneration of one of our most underdeveloped areas. It will accelerate the most extensive transformation seen in London for more than a century. Tens of thousands of 
lives will be improved by new jobs and sustainable new housing, new sports venues and other facilities (London 2012 Bid Company 2004, p. 1).

These sentiments were echoed after London had been selected as host, with the innate 'inspiration' of the Games further linked to social objectives relating to obesity, health and crime (GLA, 2009). These claims are consistent with the ways in which the sport/PA participation legacy was articulated in relation to the unique status of the Games, as in both cases the underpinning assumption is that the Olympics are capable of stimulating broad social changes that could not be achieved otherwise - which echoes MacAloon's (2008) description of the "magical properties of today's highly fetishized legacy talk in Olympic circles" (p. 2069). As much as elite sport success may be argued to increase participation and public health (Grix \& Carmichael 2012), the statements examined in this section demonstrate that the Olympics have an additional moral dimension that allows policymakers to emphasise its potential for social benefits that extend beyond sport. Along with the long-established assumptions around Olympism and sport (Chatziefstathiou \& Henry 2009), these statements about the event's special social status show how the repeated references to the 'inspiration' of the event in official legacy policy represented a specific governmental technique (Rose et al. 2006) that fitted congruently with both the stricter Olympic legacy requirements (Fussey et al. 2011) and the increasing importance of sport in government policy (Green and Houlihan, 2006).

\section{Abandonment of pre-event participation targets}

In March 2011, the UK Government admitted that the pre-event sport participation targets published by the DCMS (2008) were to be abandoned following three years of negligible progress (Gibson 2011). This acknowledgement followed reports in May 2010 that the target of one million more people participating in PA had been "quietly dropped" (Weed 
2013, p. 95). The following year, a "new approach" to the Olympic sport/PA participation legacy was published, which emphasised "reaching out to young people more effectively" (Hunt, cited in DCMS 2012, p. 1) instead of increasing mass participation. Given the ambitious rhetoric of both the bidding stage and the DCMS' formal announcement of its preevent participation targets, this policy shift represents a crucial event in the development of the legacy of London 2012.

Following the 2010 UK general election, the Labour government that had overseen the first seven years of bidding and planning for the 2012 Games was replaced by a Conservative-led coalition. Against a backdrop of national and global economic instability, the coalition government sought to justify widespread reductions in public spending in relation to the preceding Labour government's perceived fiscal irresponsibility (e.g. Landale 2013). Although these debates extended well beyond sport and the Olympic Games, the justification of coalition policy in relation to mistakes made previously by Labour - as well as the coalition's broader effort to distinguish itself from its predecessor's more target-driven approach to policy (Weed 2013) - were also evident in the abandonment and replacement of the 2008 pre-event sport/PA participation targets.

For example, the issue of how 'legacy' itself should be measured was strongly disputed. The DCMS's (2008) pre-event participation targets were announced alongside the claim that legacy includes "not just what happens after the Games, but what we do before and during them" (p. 8). Four years later, new Minister for Sport Hugh Robertson argued otherwise:

2012 is not the end of the story; it's the start of one. For us to think we could start all of this and get it done by 2012 was foolish. Government is to blame for allowing people to believe this was the date by which all this should be 
P. Bretherton et al.

judged. Legacy is what it says on the can. In 2012 we should start the legacy (Robertson, cited Gibson 2012, para. 7-8).

These competing views are consistent with recent accounts of how no clear consensus exists regarding precisely when legacy should be measured and that the term itself is inherently subjective (Leopkey \& Parent 2012b, MacAloon 2008). For SME hosts with similar political systems to the UK, this lack of clarity regarding legacy measurement has significant implications. Most importantly, the fact that one government can design legacy plans according to a specific timescale only to leave office shortly after their publication is problematic - particularly when the succeeding administration justifies wider policy changes in relation to the perceived failures of its predecessor.

Beyond the specific policy approaches of different UK Governments, rationales for the abandonment and replacement of the sport/PA participation targets also referred more broadly to the late 2000s financial crisis. For example, the central policy change around the sport/PA legacy concerned the decision to focus upon encouraging a 'habit' of sport participation in young people (DCMS 2012). This contradicted the DCMS' (2008) claim that its pre-event participation targets were intended to apply to all demographics, with specific reference made to female participation, the disabled, ethnic minorities, the elderly, and people from "more deprived areas" (p. 23). For then Culture Secretary Jeremy Hunt, this policy shift was unavoidable:

I do think it's reasonable to ask whether, with resources as constrained as they are, if it's an appropriate use of taxpayers' money to be focusing on adult participation when really what we want is to be getting young people into a habit for life (Hunt, cited Gibson 2011, para. 3). 
In this instance, the legacy planners responsible for the pre-event sport/PA participation targets were ultimately powerless in trying to ensure their realisation. This 'powerlessness' is consistent with observations about the difficulty of ensuring or 'guaranteeing' health (Vallgårda 2012; Osborne 1997) - which in this case, apply similarly to sport/PA participation. Despite the enthusiasm with which the pre-event sport/PA targets were announced and the discursive tactics (Rose et al. 2006; Foucault 1994) that were deployed in their pursuit, the attribution of their abandonment to the broader economic situation represents a clear warning for future SME hosts and legacy planners.

The ambitious nature of London's attempt to be the first Games to achieve a permanent legacy for sport/PA was also emphasised both before and after the abandonment of the initial pre-event participation targets. In 2009, the DH acknowledged that although no previous Games had brought about a "lasting increase in physical activity", London 2012 would "break new ground in delivering a health legacy" (DH 2009, p. 21). Three years later, then Culture Secretary Jeremy Hunt introduced the Coalition Government's new participation legacy plans with similar reference to the unprecedented nature of what London 2012 was attempting:

The UK has been attempting something that no other host nation has achieved - to harness the power of the Olympics and Paralympics to create a deep and lasting legacy of sports participation in every community...Yet what we've also learnt over the last six years is that there can be no 'plug and play' sporting legacy from the Games (Hunt, cited DCMS 2012a, p. 1).

The broader significance of these statements about the ambitious nature of bringing about a sport/PA participation increase lies in how the challenge of increasing participation depends upon sport/PA policy's ability to work against long-established social structures (Girginov \& 
Hills 2009) relating to the provision of sport/PA opportunities. Along with the links between the London 2012 legacy and the UK economy explored previously, this challenge provides a further example of how the planning of Olympic legacies must be sensitive to various external factors that may affect their attainment. In this case, the sentiments expressed by Hunt here had already been established in academic literature on SME legacies.

The evidence examined in this section demonstrates that despite the lofty rhetoric with which the DCMS' (2008) pre-event sport/PA participation targets were announced, their ultimate abandonment in 2011 can best be understood in terms of broader social and political factors. Three specific factors have been identified here. First, the change of UK Government in 2010 saw the Labour government that oversaw the design of the first legacy plans replaced by a coalition that sought to justify much of its policy in relation to the alleged financial irresponsibility of its predecessor. Second, this perceived irresponsibility was argued to have mitigated the effects of the late 2000s financial crisis in the UK, enabling key policymakers to rationalise the abandonment of the participation targets on economic grounds. Third, the acknowledgements of the inherent challenge of attempting to bring about the stated participation increase further emphasise the difficulty of using SMEs to attract new people to sport/PA. For future SME hosts, these three factors must all be considered in the design of policies around potential legacies. Given the extensive use of governmental 'tactics' and 'techniques' (Rose et al. 2006; Foucault 1994) geared towards the promotion of the DCMS' (2008) sport/PA participation targets, their ultimate abandonment and replacement has broader implications for how processes of government can be understood. Despite characterisations of (neo-liberal) governmentality as overly negative (Ferguson 2009), this particular example shows how there are circumstances where attempts to manage populations can be frustrated by uncontrollable environmental factors. 


\section{Conclusion}

This research aimed to understand more about how the pre-event London 2012 sport/PA participation legacy targets were constructed and reconstructed by key policy actors between 2003 and 2012. While this aspect of the event's legacy - and broader UK policy regarding sport/PA and health - have continued to develop since 2012 (e.g. DCMS 2015), this study focussed specifically upon the published intention to bring about a pre-event sport/PA participation increase, which was abandoned in 2011. For future SME hosts and policymakers, it is concluded that two sets of implications can be taken from the ultimate fate of London 2012's pre-event sport/PA participation legacy.

First, if one considers the 'tactics' (Foucault, 1994) or 'forms of knowledge' (Rose et al., 2006) that may be used in pursuit of desired individual conduct, it can be seen that although various rhetorical strategies were deployed in policy around these legacy objectives, they were ultimately ineffective. Of these strategies, two features were most apparent. The first concerned the use of scientific - or 'expert' knowledge to cast the 2012 Games as a vital opportunity to combat the 'risk' (McDermott, 2007) of obesity, alongside statements that placed more emphasis upon the various social benefits which the Games - and indeed sport more broadly - can bring. Second, the inherent 'inspiration' of the Games - premised upon these deeper assumptions around sport (e.g. Smith \& Westerbeek, 2007) - was enthusiastically presented as affording the event a special capacity to increase sport/PA participation in addition to addressing numerous wider social issues for the better. As has been suggested previously (e.g. Weed et al. 2012), host governments cannot rely on the event alone to increase or 'inspire' participation. As befits the status of the Games as a "genuine public policy concern" (Chappelet \& Kübler-Mabbott 2008, p. 91), social legacies such as sport/PA participation must therefore be pursued much more proactively. 
Second, the ultimate abandonment of these pre-event targets and their accompanying policies should not be attributed exclusively to their own limitations, but also to a range of external environmental factors. The subsequent DCMS assertions that the measurement, target population and timescale of the pre-event targets were fundamentally flawed are consistent with claims that Olympic legacy is best viewed as a product of social and political processes that can be seen to evolve over time (Leopkey \& Parent 2012b; Girginov \& Hills 2009; 2008) as well as (ultimately vindicated) academic warnings of the difficulties of using the Games to increase sport/PA participation (e.g. Coalter 2004, Veal 2003, Bauman et al. 2001). Future Olympic hosts and legacy planners can learn from the fact that these empirical sources were overridden by such dominant 'styles of thought' (Rose et al. 2006) and popular assumptions. However, where previous analyses may have tended towards an overly negative usage of governmentality in relation to neo-liberal societies (Ferguson 2009), the example of policy abandonment examined here demonstrates how the power of governing actors must be set against the competing influences of external and uncontrollable social factors.

As this research focuses specifically upon pre-event legacy policy, these conclusions do not apply to SMEs on a post-event basis. Further research will be required to evaluate the post-event success of the London 2012 sport/PA participation legacy and its implications for other SMEs. Furthermore, the UK's status as a developed country with a Western democratic model of government that fully acknowledges sport's role in public policy (Green \& Houlihan 2006) should also be acknowledged. SMEs are increasingly being held in nations that differ markedly; as demonstrated by the hosting of the 2016 Summer Olympic Games by Rio de Janeiro, Brazil and the 2022 FIFA World Cup by Qatar, and future research should be both sensitive to these differences and aware of the value of examining the policy issues addressed by this research in new environments. 


\section{Bio Notes}

Paul Bretherton was awarded a PhD in Sport and Leisure Policy from Loughborough University, UK in 2014. His research focuses mainly on the Olympic Games and sport mega events, sport sponsorship and Corporate Social Responsibility in sport.

Joe Piggin is a Senior Lecturer in Sport Management and Policy at Loughborough University, UK.

Guillaume Bodet is a Professor at Université Claude Bernard Lyon-1, France.

\section{References}

Agha, N., Fairley, S., Gibson, H., 2011. Considering legacy as a multi-dimensional construct: The legacy of the Olympic Games. Sport management review, 15(1), 125-139.

Bauman, A., Ford, I. \& Armstrong, T., 2001. Trends in population levels of reported physical activity in Australia, 1997, 1999 and 2000. Australia: Australian Sports Commission

Braun, V. \& Clarke, V., 2006. Using thematic analysis in psychology. Qualitative research in psychology, 3, 77-101.

Burgan, B. \& Mules, T., 1992. Economic impact of sporting events. Annals of tourism research, 19(4), 700-710.

Bullough, S.J., 2012. A new look at the latent demand for sport and its potential to deliver a positive legacy for London 2012. International journal of sport policy and politics, $4(1), 39-54$.

Cashman, R., 1999. Beyond the games. In R. Cashman \& A. Hughes (Eds.) Staging the Olympics: The event \& its impact (pp. 183-94). Netley: Griffin

Charlton, T., 2010. 'Grow and Sustain': the role of community sports provision in promoting a participation legacy for the 2012 Olympic Games, International journal of sport policy and politics, 2(3), 347-366.

Chappelet, J., 2012. Mega sporting event legacies: A multifaceted concept. Papeles de Europa, 25, 76-86.

Chappelet, J. \& Kübler-Mabbott, B., 2008. The International Olympic Committee and the Olympic System: The governance of world sport. Great Britain: Routledge

Chatziefstathiou, D. \& Henry, I., 2009. Technologies of power, governmentality and Olympic discourses: A Foucauldian analysis for understanding the discursive constructions of the Olympic ideology, Esporte e sociedade, 4(12), 1-28. 
Coalter, F., 2004. Stuck in the blocks? A sustainable sporting legacy. In A. Vigor, M. Mean \& C. Tims (Eds.) After the gold rush: A sustainable Olympics for London (pp.91 106). Report produced by Demos and ippr.

Commission for a Sustainable London 2012, 2011. Fit for purpose? A review of inclusion and healthy living across the 2012 programme. Great Britain: Commission for a Sustainable London 2012

Dean, M., 1999. Governmentality: Power and rule in modern society. Great Britain: Sage Publications

Department for Culture, Media and Sport, 2011. Report 1: Scope, research questions and data strategy: Meta-evaluation of the impacts and legacy of the London 2012 Olympic and Paralympic Games London: DCMS

Department for Culture, Media and Sport, 2010. Plans for the legacy from the 2012 Olympic and Paralympic Games. London: DCMS

Department for Culture, Media and Sport, 2008. Before, during and after: Making the most of the London 2012 Games. London: DCMS

Department for Health, 2011. The public health responsibility deal. London: DH

Department for Health, 2009. Be active be healthy: A plan for getting the nation moving. London: DH

Devine, C., 2013. London 2012 Olympic legacy: a big sporting society? International journal of sport policy and politics, 5(2), 257-279.

Ferguson, J., 2009. The uses of neoliberalism. Antipode, 41, 166-184.

Foucault, M., 1994. Governmentality. In J.D. Faubion (Ed.) Power: The essential works of Foucault 1954-1984 (pp. 201-222). England: Penguin

Fussey, P., Coaffee, J., Armstrong, G. \& Hobbs, D., 2011. Securing and sustaining the Olympic City: Reconfiguring London for 2012 and beyond. Great Britain: Ashgate

Gibson, O., 2012. Hugh Robertson admits to struggling with legacy for grassroots sport. The Guardian. Retrieved from http://www.theguardian.com/sport/2012/mar/05/hugh robertson legacy games 2012

Girginov, V. \& Hills, L., 2009. The political process of constructing a sustainable London Olympics sports development legacy. International journal of sport policy and politics, 1(2), 161-181.

Girginov, V. \& Hills, L., 2008. A Sustainable Sports Legacy: Creating a Link between the London Olympics and Sports Participation. International journal of the history of sport, 25(14), 20910-2116.

Gratton, C. \& Preuss, H., 2008. Maximizing Olympic impacts by building up legacies. The international journal of the history of sport, 25, 1922-1938. 
Greater London Authority, 2009. A Sporting Future for London? Retrieved from http://www.london.gov.uk/sites/default/files/a\%20sporting\%20legacy\%20for\%20Lo don.pdf

Green, M. \& Houlihan, B., 2006. Governmentality, modernization, and the "disciplining" of national sporting organisations: Athletics in Australia and the United Kingdom. Sociology of Sport Journal, 23, 47-71.

Grix, J., 2015. Sport politics: An introduction. Palgrave: Great Britain

Grix, J. \& Carmichael, F., 2012. Why do governments invest in elite sport? A polemic. International Journal of Sport Policy \& Politics, 4(1), 73-90.

Harrison, L., 2001. Political research: An introduction. Great Britain: Routledge

Heynen, N., McCarthy, J. Prudham, S. \& Robbins, P., 2007. Neoliberal environments: false promises and unnatural consequences. Great Britain: Routledge

Hindson, A., Gidlow, B. \& Peebles, C., 1994. The 'trickle down effect' of top level sport: Myth or reality? A case study of the Olympics. Australian journal of leisure and recreation, 4(1), 16-24.

International Olympic Committee, 2013a. Olympic Charter. Retrieved from http://www.olympic.org/Documents/olympic_charter_en.pdf

International Olympic Committee, 2013b. Olympic Games: Legacies and Impacts. IOC Library.

Kay, T., 2012. Accounting for legacy: Monitoring and evaluation in sport in development relationships. Sport in society: Cultures, commerce, media, politics, 15(6), 888-904.

Kelso, P., 2011. London 2012: Sport England to miss legacy target as Games fail to inspire youngsters. The Telegraph. Retrieved from http://www.telegraph.co.uk/sport/olympics/news/8944428/London 2012-OlympicsSport England-to-miss-legacy-target-as-Games-fail-to-inspire-youngsters.html

Landale, J. 2013. David Cameron: Labour's the point. BBC News. Retrieved from http://www.bbc.co.uk/news/uk-politics-24371521

Lenskyj, H., 2000. Inside the Olympic industry: Power, politics and activism. USA: State University of New York Press

London 2012, 2009. Towards a one planet 2012. London: London 2012

London 2012, 2005. Singapore presentation. Presented at $117^{\text {th }}$ International Olympic Committee Session, 6 July 2005.

London 2012, 2004. London 2012 candidate file. London 2012: London 2012 
Leopkey, B., \& Parent, M. M., 2012a. Olympic Games Legacy: From general benefits to sustainable long-term legacy. The international journal of the history of sport, $\quad 29$, 924-943.

Leopkey, B. \& Parent, M.M., 2012b. The (neo) institutionalization of legacy and its sustainable governance within the Olympic Movement. European sport management quarterly, 12(5), 437-455.

MacAloon, J.J., 2008. 'Legacy' as managerial/magical discourse in contemporary Olympic affairs. The international journal of the history of sport, 25(14), 2060-2071.

Mahtani, K.R., Protheroe, J., Slight, S.P., Demarzo, M.M.P., Blakeman, T., Barton, C.A., Brijnath, B. \& Roberts, N., 2013. Can the London 2012 Olympics 'inspire a generation' to do more physical or sporting activities? An overview of systematic reviews. British medical journal open, 3:e002058.

McCartney, G., Thomas, S., Thomson, H., Scott, J., Hamilton, V., Hanlon, P., Morrison, D.S. \& Bond, L, 2010. The health and socioeconomic impacts of major multi-sport events: systematic review (1978-2008). British medical journal, 340, c2369.

McDermott, L., 2007. A Governmental Analysis of Children "at Risk" in a world of physical inactivity and obesity epidemics. Sociology of sport journal, 24, 302324.

Murphy, N.M. \& Bauman, A., 2007. Mass sporting events and physical events - are they "bread and circuses" or public health interventions to increase population levels of physical activity? Journal of physical activity and health, 4, 193-202.

Osborne, T., 1997. Of health and statecraft. In A. Petersen and R. Bunton (Eds.) Foucault: Health and medicine (pp.173-188). Great Britain: Routledge

Piggin, J., Jackson, S.J. \& Lewis, M., 2009. Knowledge, Power and Politics. International review for the sociology of sport, 44, 87-101.

Rose, N., O'Malley, P. \& Valverde, M., 2006. Governmentality. Annual review of law and social science, 2, 83-104.

Silverman, D., 2010. Doing qualitative research. Great Britain: Sage

Slater, M. 2010. Lottery boost for London 2012 mass participation legacy. Retrieved from http://news.bbc.co.uk/sport1/hi/olympic_games/london_2012/9190546.stm

Smith, A.C.T. \& Westerbeek, H.M., 2007. Sport as a vehicle for deploying corporate social responsibility. Journal of corporate citizenship, 25, 43-54.

Sport England, 2014. Get healthy get active: What we've learnt so far April 2013-July 2014. London: Sport England

Sport England, 2008. Sport England strategy 2008-2011. London: Sport England

Tsuoros, A.D. Stergachis, A. Barbeschi, M., Tsiodras, S., Knebel, A. \& Efstathiou, P.A., 2007. The Athens 2004 Olympic Games and public health: Main conclusions and 
lessons learned. In A.D. Tsouros \& P.A. Efstathiou (Eds.) Mass gatherings and public health: The experience of the Athens 2004 Olympic Games (pp. 303-310). Denmark: World Health Organisation Regional Office for Europe

UK Government, 2014. Sporting future: A new strategy for an active nation. London: UK Government

Vallentin, S. \& Murillo, D., 2011. CSR as governmentality. Paper submitted for the $4^{\text {th }}$ Isbee World Congress, Cape Town, South Africa, 15-18 July 2008.

Vallgårda, S., 2012. Nudge-a new and better way to improve health? Health policy, 104, 200-203.

Veal, A.J., 2003. Tracking change: Leisure participation and policy in Australia, 1985-2002. Annals of leisure research, 6(3), 245-277.

Weed, M., 2013. London 2012 legacy strategy: Ambitions, promises and implementation plans. In V. Girginov (Ed.) Handbook of the London 2012 Olympic and Paralympic Games (Volume One) (pp. 87-98). Great Britain: Routledge

Weed, M., Coren, E., Fiore, J., Wellard, I., Mansfield, L., Chatziefstathiou, D. \& Dowse, S., 2012. Developing a physical activity legacy from the London 2012 Olympic and Paralympic Games: a policy-led systematic review. Perspective public health, 132(2), 75-80.

Weed, M., Coren, E., Fiore, V., Mansfield, L., Wellard, I., Chatziefstathiou, D. \& Dowse, S. (2009). A systematic review of the evidence base for developing a physical activity and health legacy from the London 2012 Olympic and Paralympic Games. London: Department for Health

Weiler, R. \& Stamatakis, E., 2010. Physical activity in the UK: A unique crossroad? British journal of sports medicine, 44, 912-914.

Wellings, K., Datta, J., Wilkinson, P. \& Petticrew, M., 2011. The 2012 Olympics: Assessing the public health effect. The Lancet, 378(9797), 1193-1195. 